\title{
Islet Cell Associated Autoantibodies and C-Peptide Levels in Patients with Diabetes and Symptoms of Gastroparesis
}

Elias S. Siraj ${ }^{*}$, Carol Homko², Laura A. Wilson³, Patrick May ${ }^{3}$, Ajay D. Rao², Jorge Calles, Gianrico Farrugia ${ }^{5}$, William L. Hasler, Kenneth L. Koch ${ }^{7}$, Linda Nguyen, William J. Snape, Thomas L. Abell' ${ }^{10}$, Irene Sarosiek ${ }^{11}$, Richard W. McCallum ${ }^{11}$, Pankaj J. Pasricha ${ }^{3}$, John Clarke ${ }^{3}$, James Tonascia ${ }^{3}$, Frank Hamilton ${ }^{12}$ and Henry P. Parkman ${ }^{2}$

\footnotetext{
'Division of Endocrinology and Metabolic Disorders, Eastern Virginia Medical School, Norfolk, VA, United States, ${ }^{2}$ Lewis Katz School of Medicine, Temple University, Philadelphia, PA, United States, ${ }^{3}$ Johns Hopkins University, Baltimore, MD, United States, ${ }^{4}$ Case Western Reserve University, Cleveland, OH, United States, ${ }^{5}$ Mayo Clinic, Rochester, NY, United States, ${ }^{6}$ University of Michigan, Ann Arbor, MI, United States, ${ }^{7}$ Wake Forest University, Winston-Salem, NC, United States, ${ }^{8}$ Stanford University, Palo Alto, CA, United States, ${ }^{9}$ California Pacific Medical Center, San Francisco, CA, United States, ${ }^{10}$ University of Louisville, Louisville, KY, United States, ${ }^{11}$ Texas Tech University Health Science Center, El Paso, TX, United States, ${ }^{12}$ National Institute of Diabetes and Digestive and Kidney Diseases, Bethesda, MD, United States
}

\section{OPEN ACCESS}

Edited by:

Åke Sjöholm,

Gävle Hospital, Sweden

Reviewed by:

Aaron Hanukoglu,

Tel Aviv University, Israel

William Augustine Toscano,

University of Minnesota,

United States

${ }^{*}$ Correspondence:

Elias S. Siraj

sirajes@evms.edu

Specialty section:

This article was submitted

to Diabetes,

a section of the journal

Frontiers in Endocrinology

Received: 19 October 2017 Accepted: 23 January 2018 Published: 13 February 2018

Citation:

Siraj ES, Homko C, Wilson LA, May P, Rao AD, Calles J, Farrugia G,

Hasler WL, Koch KL, Nguyen L,

Snape WJ, Abell TL, Sarosiek I, McCallum RW, Pasricha PJ, Clarke J,

Tonascia J, Hamilton F and

Parkman HP (2018) Islet Cell

Associated Autoantibodies and

C-Peptide Levels in Patients with

Diabetes and Symptoms of

Gastroparesis.

Front. Endocrinol. 9:32.

doi: 10.3389/fendo.2018.00032
Introduction: Individuals with diabetes are at increased risk for complications, including gastroparesis. Type 1 diabetes mellitus (T1DM) is an autoimmune disorder resulting in decreased beta-cell function. Glutamic acid decarboxylase-65 antibody (GADA) is the most commonly used test to assess autoimmunity while C-peptide level is used to assess beta-cell function. Patients with type 2 diabetes mellitus (T2DM), who are GADA positive, are labeled latent autoimmune diabetes in adults (LADA).

Objective: To characterize patients with $\mathrm{T} 1$ and T2DM who have symptoms of gastroparesis using GADA and C-peptide levels and to look for association with the presence of gastroparesis and its symptom severity.

Design: 113 T1DM and 90 T2DM patients with symptoms suggestive of gastroparesis were studied. Symptom severity was assessed using Gastroparesis Cardinal Symptom Index (GCSI). Serum samples were analyzed for GADA and C-peptide.

Results: Delayed gastric emptying was present in 91 (81\%) of T1DM and 60 (67\%) of T2DM patients $(p=0.04)$. GADA was present in $13 \%$ of T2DM subjects [10\% in delayed gastric emptying and $20 \%$ in normal gastric emptying $(p=0.2)$ ]. Gastric retention and GCSI scores were mostly similar in GADA positive and negative T2DM patients. GADA was present in $45 \%$ of T1DM subjects [ $46 \%$ in delayed gastric emptying and $41 \%$ in normal gastric emptying $(p=0.81)$ ]. Low C-peptide levels were seen in 79\% T1DM patients and 8\% T2DM. All seven T2DM patients with low C-peptide were taking insulin compared to $52 \%$ of T2DM with normal C-peptide.

Conclusion: GADA was present in 13\% while low C-peptide was seen in $8 \%$ of our T2DM patients with symptoms of gastroparesis. Neither did correlate with degree of delayed gastric emptying or symptom severity.

ClinicalTrials.gov Identifier: NCT01696747.

Keywords: GAD, GAD65, GAD65 antibodies, islet cell antibodies, C-peptide, gastroparesis, diabetic gastroparesis, gastric emptying 


\section{INTRODUCTION}

Type 1 diabetes mellitus (T1DM) is an autoimmune disorder (with evidence of autoantibodies) and decreased beta-cell function (measured using C-peptide levels), whereas Type 2 diabetes (T2DM) results from a combination of insulin resistance and diminished beta-cell function. However, some patients with T2DM are found to have positive autoantibody profile [often positive glutamic acid decarboxylase-65 antibody (GADA)] suggesting they may have latent autoimmune diabetes in adults (LADA) (1). In studies specific to North America, LADA has been reported in $3-20 \%$ of patients initially thought to have $\operatorname{T} 2 \mathrm{DM}(2,3)$.

The presence of LADA in patients clinically considered to have T2DM at diagnosis is found to be associated with a progression to beta-cell failure requiring insulin within few years (4). Individuals with LADA have worse glycemic control than patients with T2DM (5). In addition, it has been reported that LADA patients may have a higher prevalence of complications, particularly retinopathy and nephropathy than T2DM (4).

Gastroparesis is another complication of long-standing diabetes characterized by delayed gastric emptying. Approximately $25-55 \%$ of T1DM develop gastroparesis (6). However, gastroparesis is being increasingly diagnosed in type 2 diabetes (T2DM) patients as well with prevalence rate of about 30\% (6). A recent study indicated that patients with generalized autoimmune dysautonomia may also present with gastroparesis. Immune dysfunction in such patients can be evaluated using antibodies to glutamic acid decarboxylase (GADA) (7). It is, therefore, interesting to look if presence of GADA in both T1 and T2DM is associated with the presence and severity of gastroparesis.

The aim of this study was to characterize patients with diabetes who have symptoms of gastroparesis using GADA and C-peptide levels to help determine if these correlate with delayed gastric emptying and symptoms, better than the clinical classification of T1DM and T2DM. We also wanted to test the hypothesis that patients with T2DM who are GADA positive are more likely to develop gastroparesis. We are hypothesizing that patients with an autoimmune form of diabetes, whether T1DM or T2DM, may be at a higher risk of developing gastroparesis.

\section{MATERIALS AND METHODS}

This study is a secondary analysis of data from the Gastroparesis Clinical Research Consortium (GpCRC) Registry $(8,9)$. The NIDDK GpCRC has a large number of carefully evaluated patients with diabetes and gastroparesis, as well as a number of patients with diabetes with symptoms of gastroparesis but normal gastric emptying. The GpCRC Gastroparesis Registry (GpR) was established in 2006 as an observational study to investigate the etiology, epidemiology, and degree of morbidity with gastroparesis. The second NIDDK GpR (GpR2) was started in 2013, collecting more physiologic testing. Classification of type of diabetes for the registry was obtained from the patient's medical record and/or in some cases by patient self-report.

The registry collected extensive clinical data on patients in order to fully characterize the features of their gastroparesis. These include a complete medical history, physical examination, gastric emptying scintigraphy (GES), validated symptom questionnaires including Patient Assessment of Upper Gastrointestinal Disorders Symptoms Severity Index (PAGI-SYM) (10) and laboratory tests, including glucose and glycosylated hemoglobin levels. The history asked about the use of insulin and the presence of peripheral neuropathy. Fasting serum and plasma had been stored and were utilized to assess GADA and C-peptide levels for this study.

\section{Laboratory Analysis}

Serum samples were analyzed for GADA and C-peptide levels. The assays were performed through Quest Diagnostics Research Laboratory. GADA levels were measured using a radiobinding assay. The reference value for GADA was $\leq 1.0 \mathrm{U} / \mathrm{ml}$. C-peptide levels were measured using an immunoassay. The reference range was $0.80-3.10 \mathrm{ng} / \mathrm{ml}$.

\section{Patient Assessment of GI Symptoms (PAGI-SYM)}

The PAGI-SYM questionnaire assessed 24 symptoms of gastroparesis, dyspepsia, gastroesophageal reflux disease with the severity over the last 2 weeks rated by the patient as none $=0$ to very severe $=5(0=$ none, $1=$ very mild, $2=$ mild, $3=$ moderate, $4=$ severe, $5=$ very severe) (10). This PAGI-SYM contains the nine symptoms comprising the Gastroparesis Cardinal Symptom Index (GCSI) (11). Patients were also asked about their most prominent symptom.

\section{Gastric Emptying Scintigraphy}

Gastric emptying scintigraphy was performed using a low-fat, egg white meal with imaging at $0,1,2$, and $4 \mathrm{~h}$ after meal ingestion (12). This protocol ensured standardized information about gastric emptying across multiple sites. Patients are instructed to stop medications that could affect gastrointestinal motility for $48 \mathrm{~h}$ prior to the study and to come to the Nuclear Medicine Section in the morning after fasting overnight, that is, an 8 -h fast. Patients with diabetes have their glucose checked at the beginning of the study, with appropriate treatment measures being taken if low blood sugar (hypoglycemia $<60 \mathrm{mg} / \mathrm{dl}$ ) or high blood sugar (hyperglycemia $>250 \mathrm{mg} / \mathrm{dl}$ ) is detected. GES is performed using a standard low-fat, Eggbeaters ${ }^{\circledR}$ meal to measure solid emptying. The meal consists of the equivalent of two large eggs radiolabeled with $0.5-1 \mathrm{mCi}$ Tc-99m sulfur colloid served with two pieces of white bread and jelly. Patients are given $120 \mathrm{ml}$ water. Following ingestion of the meal, imaging is performed at $0,1,2$, and $4 \mathrm{~h}$ with the patient upright for measuring gastric emptying of Tc-labeled solids. Gastric emptying is analyzed as percent of radioactivity retained in the stomach over time using the geometric center of the decay-corrected anterior and posterior counts for each time point. Gastric retention of Tc- $99 \mathrm{~m}>60 \%$ at $2 \mathrm{~h}$ and/or $>10 \%$ at $4 \mathrm{~h}$ is considered delayed gastric emptying of solids (12).

\section{Statistical Methods}

Descriptive statistics (means, SDs, frequencies, and percentages) were used to compare subgroups of gastroparesis patients. 
Enrollment characteristics such as demographics, medical history, gastroparesis history, diabetes history and treatment, symptom severity were compared by etiology (T1DM vs T2DM). Within the groups of $\mathrm{T} 1$ and T2DM, enrollment characteristics were also compared by the subgroups of patients with positive GAD65 vs negative GAD65 and for subgroups of patients with low vs normal C-peptide levels. $p$-Values were determined from Fisher's exact tests for categorical variables and $t$-tests for continuous variables. All $p$-values are two-sided; values $<0.05$ were considered statistically significant. Analyses were performed using methods described in SAS version 9.3 (SAS Institute) or Stata version 13.1 (StataCorp).

\section{RESULTS}

A total of 203 patients with diabetes (113 patients with T1DM and 90 patients with T2DM) having symptoms suggestive of gastroparesis from the NIDDK GpR were assessed in this study.

\section{Comparing T1DM vs T2DM}

Table 1 shows the baseline characteristics of patients by type of diabetes. As expected, T2DM patients were older, had higher BMI, and less often used insulin compared to T1DM patients. At enrollment into the registry, T1DM patients had a longer duration of diabetes and longer duration of gastroparesis than T2DM patients. At enrollment, 108 (95.6\%) of T1DM and 50 (55.6\%) of T2DM were using insulin. A1c levels were higher in T1DM $(8.2 \pm 1.8 \%)$ than T2DM $(7.6 \pm 1.8 \%, p=0.02)$. GADA were present in $50(45 \%)$ of T1DM and $12(13 \%)$ of T2DM. Low C-peptide levels were seen in $88(79 \%)$ of T1DM patients and 7 (8\%) of T2DM.

Delayed gastric emptying was present in 91 (81\%) of T1DM and $60(67 \%)$ of T2DM patients $(p=0.04)$. Total gastroparesis symptoms (GCSI) were similar between T1DM $(2.9 \pm 1.1)$ and T2DM $(3.0 \pm 1.0 ; p=0.66)$, though vomiting was more severe in T1DM $(2.6 \pm 1.9$ vs $2.0 \pm 1.8 ; p=0.01)$ and early satiety marginally more severe in T2DM ( $3.3 \pm 1.4$ vs $2.8 \pm 1.6 ; p=0.05)$.

\section{Comparing Glutamic Acid Decarboxylase-65 Antibody (GADA) Positive vs GADA Negative Subjects}

Table 2 shows comparison of baseline characteristics between GADA positive and GADA negative subgroups within T1DM. In relative terms, whites were overrepresented in the GADA positive group while Blacks were overrepresented in the GADA negative group $(p=0.004)$. Between the two groups, there was no significant difference in duration of gastroparesis symptoms, gastric emptying or GI symptoms. Low C-peptide levels were seen in $43(88 \%)$ of GADA positive and 45 (73\%) of GADA negative subjects.

Table 3 shows comparison of baseline characteristics between GADA positive and GADA negative subgroups within T2DM. GADA positive subjects with T2DM, compared to GADA negatives, had a longer duration of gastroparesis $(7.1 \pm 6.7$ vs $3.8 \pm 2.9$ years; $p=0.004)$, marginally lower prevalence of peripheral neuropathy ( 8.3 vs $39.7 \%$; $p=0.05$ ), and were more likely to be Hispanic (42 vs 9\%; $p=0.009$ ). Regarding symptoms, upper abdominal pain was higher in GADA positive subjects $(3.7 \pm 1.6$ vs $2.5 \pm 1.7 ; p=0.03$ ) but the rest of the symptoms and gastric emptying results were similar.

\section{Comparison by Gastric Emptying Results within T2DM}

Table 4 shows comparison of baseline characteristics between those with normal gastric emptying vs those with delayed gastric emptying subgroups within T2DM. Females were marginally overrepresented in the delayed gastric emptying group $(p=0.08)$. GADA was present in $13 \%$ of T2DM subjects [ $10 \%$ in delayed gastric emptying and $20 \%$ in normal gastric emptying $(p=0.2)$ ]. There was no significant difference in GADA positivity or the frequency of low C-peptide between the two groups.

\section{Comparison by Gastric Emptying Results within T1DM}

Glutamic acid decarboxylase-65 antibody was present in $45 \%$ of T1DM subjects [ $46 \%$ in delayed gastric emptying and $41 \%$ in normal gastric emptying $(p=0.81)]$. Low C-peptide levels were seen in $79 \%$ of T1DM [ $79 \%$ in delayed gastric emptying and $82 \%$ in normal gastric emptying $(p=1.00)]$. The full comparison is shown on Table 5.

\section{Comparing Low C-Peptide vs Normal/High C-Peptide Subjects}

Table 6 shows comparison of baseline characteristics between low C-peptide and normal/high C-peptide subgroups within T1DM. Of all T1DM patients, 88 (79\%) had low C-peptide levels while the rest 23 (21\%) had normal/high C-peptide levels, indicating the limitations of clinical classification. All of the 88 subjects with low C-peptide levels (100\%) were taking insulin, compared to only $18(78 \%)$ of those with normal/high C-peptide $(p<0.001)$. GADA positivity was marginally higher in the low C-peptide group $(p=0.06)$. There were no significant differences between the two groups in gastric emptying as well as in symptoms.

We compared the baseline characteristics between low C-peptide and normal/high C-peptide subgroups within T2DM. Of all T2DM patients, 7 (7.7\%) had low C-peptide levels while the rest 83 (92.3\%) had normal/high C-peptide levels. All of the seven subjects with low C-peptide levels (100\%) were taking insulin, compared to only 43 (51\%) of those with normal/high C-peptide. GADA positivity was not significantly different between the two groups. There were no significant differences between the two groups in gastric emptying, but the severity of bloating and visibly larger stomach was greater in those with normal/high C-peptide levels. The significance of this data is limited due to the small number of patients with T2DM who have low C-peptide levels.

\section{DISCUSSION}

The classification between T1DM and T2DM is generally done using clinical criteria. Occasionally, GADA and C-peptide levels are measured to help differentiate between the two. Generally, GADA positivity and low C-peptide levels are considered as 
TABLE 1 | Baseline characteristics patients by diabetes type [Type 1 diabetics (T1DM) vs Type 2 diabetics (T2DM)].

\begin{tabular}{|c|c|c|c|}
\hline Baseline characteristic & $\begin{array}{c}\text { Type } 1 \text { diabetes }(n=113) \\
N(\%) \text { or mean } \pm \text { SD }\end{array}$ & $\begin{array}{l}\text { Type } 2 \text { Diabetes }(n=90) \\
N(\%) \text { or mean } \pm \text { SD }\end{array}$ & $p$-Value \\
\hline \multicolumn{4}{|l|}{ Demographic } \\
\hline Gender: female & $78(69.0)$ & 66 (73.3) & 0.54 \\
\hline Mean age at enrollment & $40.3 \pm 12.1$ & $52.0 \pm 9.9$ & $<0.001$ \\
\hline Ethnicity: Hispanic vs other & $17(15.0)$ & 12 (13.3) & 0.84 \\
\hline Race & & & 0.83 \\
\hline White & $84(75.7)$ & $70(78.7)$ & \\
\hline Black & $21(18.9)$ & $16(18.0)$ & \\
\hline Other & $6(5.4)$ & $3(3.4)$ & \\
\hline \multicolumn{4}{|l|}{ Anthropometric } \\
\hline $\mathrm{BMI}\left(\mathrm{kg} / \mathrm{m}^{2}\right)$ & $26.9 \pm 6.3$ & $33.3 \pm 7.8$ & $<0.001$ \\
\hline \multicolumn{4}{|l|}{ Medical history } \\
\hline Age at diabetes diagnosis (years) & $18.4 \pm 11.1$ & $39.6 \pm 10.5$ & $<0.001$ \\
\hline Duration of diabetes at enrollment (years) & $21.9 \pm 12.2$ & $12.4 \pm 7.6$ & $<0.001$ \\
\hline Presence of peripheral neuropathy & $53(46.9)$ & 32 (35.6) & 0.12 \\
\hline Use of insulin & $108(95.6)$ & $50(55.6)$ & $<0.001$ \\
\hline Onset of symptoms & & & 0.29 \\
\hline Acute start & $55(48.7)$ & $46(51.1)$ & \\
\hline Insidious & $58(51.3)$ & $42(46.7)$ & \\
\hline Glucose (mg/dl) & $174.9 \pm 88.0$ & $148.5 \pm 71.9$ & 0.02 \\
\hline $\mathrm{HbA1c}(\%)$ & $8.2 \pm 1.8$ & $7.6 \pm 1.8$ & 0.02 \\
\hline \multicolumn{4}{|l|}{ History of gastroparesis } \\
\hline Age at diagnosis of gastroparesis (years) & $34.0 \pm 11.3$ & $47.7 \pm 10.5$ & $<0.001$ \\
\hline Duration of gastroparesis at enrollment (years) & $6.7 \pm 6.2$ & $4.3 \pm 3.7$ & 0.001 \\
\hline \multicolumn{4}{|l|}{ Gastric emptying (mean\% retained) } \\
\hline 2-h emptying & $61.0 \pm 26.9$ & $48.4 \pm 25.3$ & $<0.001$ \\
\hline 4-h emptying & $37.3 \pm 29.4$ & $21.4 \pm 21.2$ & $<0.001$ \\
\hline Delayed gastric emptying a & $91(80.5)$ & $60(66.7)$ & 0.04 \\
\hline \multicolumn{4}{|l|}{ Islet autoantibodies } \\
\hline GADA > 1.0 U/ml (positive) & $50(44.6)$ & $12(13.3)$ & $<0.001$ \\
\hline C-Peptide, low ( $\leq 0.8$ ng/ml) & $88(79.3)$ & $7(7.8)$ & $<0.001$ \\
\hline \multicolumn{4}{|l|}{ PAGI-SYM symptom severity (0-5) } \\
\hline Nausea severity & $3.4 \pm 1.3$ & $3.1 \pm 1.3$ & 0.18 \\
\hline Retching severity & $2.4 \pm 1.7$ & $2.2 \pm 1.6$ & 0.43 \\
\hline Vomiting severity & $2.6 \pm 1.9$ & $2.0 \pm 1.8$ & 0.01 \\
\hline Feeling of stomach fullness severity & $3.3 \pm 1.5$ & $3.6 \pm 1.2$ & 0.08 \\
\hline Inability to finish meal severity & $2.8 \pm 1.6$ & $3.3 \pm 1.4$ & 0.05 \\
\hline Excessively full after meal severity & $3.4 \pm 1.5$ & $3.6 \pm 1.2$ & 0.23 \\
\hline Loss of appetite severity & $2.8 \pm 1.6$ & $2.8 \pm 1.5$ & 0.96 \\
\hline Bloating severity & $3.0 \pm 1.6$ & $3.4 \pm 1.5$ & 0.07 \\
\hline Visibly larger stomach severity & $2.7 \pm 1.7$ & $2.9 \pm 1.7$ & 0.27 \\
\hline Upper abdominal pain & $2.8 \pm 1.8$ & $2.7 \pm 1.7$ & 0.58 \\
\hline Upper abdominal discomfort & $2.9 \pm 1.7$ & $2.9 \pm 1.6$ & 0.83 \\
\hline Cardinal symptom index (GCSI) (0-5) & $2.9 \pm 1.1$ & $3.0 \pm 1.0$ & 0.66 \\
\hline Nausea/vomiting GCSI subscale & $2.8 \pm 1.5$ & $2.4 \pm 1.3$ & 0.06 \\
\hline Bloating GCSI subscale & $2.8 \pm 1.6$ & $3.2 \pm 1.6$ & 0.14 \\
\hline Postprandial fullness GCSI subscale & $3.1 \pm 1.2$ & $3.3 \pm 1.1$ & 0.15 \\
\hline
\end{tabular}

${ }^{a}$ Gastric emptying scintigraphy of $>60 \%$ at $2 h$ OR $>10 \%$ at $4 \mathrm{~h}$.

GCSI, Gastroparesis Cardinal Symptom Index.

indicators of the presence of T1DM. GADA positivity, which could be seen in $>80 \%$ of T1DM patients at the time of diagnosis, tends to decline over time. On the other side, a minority of T2DM patients have been recognized to have GADA positivity and low $\mathrm{C}$-peptide levels. The name latent autoimmune diabetes in adults (LADA) has been used to denote those subjects, who also tend to demonstrate some phenotypic features of T1DM.

About $21 \%$ of T1DM subjects did not have low C-peptide levels and about $4 \%$ were not on insulin. It is possible that some of those subjects may have been wrongly classified based on clinical parameters. On the other hand, only $45 \%$ of T1DM subjects were GADA positive, which is acceptable given the fact that the duration of diabetes was about 21 years, leading to lower positivity.

Our analysis showed that T1DM subjects had longer duration of symptoms and more prevalent delayed gastric emptying than T2DM, but total symptom scores were mostly similar. The only significant difference in symptoms was seen in vomiting, which was more prevalent in T1DM. These data support a prior publication of ours looking at the baseline characteristics and course of T1DM vs T2DM patients (13). 
TABLE 2 | Baseline characteristics of patients with T1DM by level of GAD-65 Antibodies.

\begin{tabular}{|c|c|c|c|}
\hline Baseline characteristic & $\begin{array}{l}\text { Positive GAD-65 Antibodies } \\
\text { (GADA > 1.0) }(n=50) \\
N(\%) \text { or mean } \pm \text { SD }\end{array}$ & $\begin{array}{c}\text { Negative GAD-65 Antibodies } \\
\text { (GADA } \leq 1.0)(n=62) \\
N(\%) \text { or mean } \pm \text { SD }\end{array}$ & $p$-Value \\
\hline \multicolumn{4}{|l|}{ Demographic } \\
\hline Gender: female & $36(72.0)$ & $41(66.1)$ & 0.54 \\
\hline Mean age at enrollment & $40.6 \pm 12.4$ & $40.4 \pm 11.8$ & 0.93 \\
\hline Ethnicity: Hispanic vs other & $8(16.0)$ & $9(14.5)$ & 1.00 \\
\hline Race & & & 0.004 \\
\hline White & $45(90.0)$ & $39(65.0)$ & \\
\hline Black & $3(6.0)$ & $17(28.3)$ & \\
\hline Other & $2(4.0)$ & $4(6.7)$ & \\
\hline \multicolumn{4}{|l|}{ Anthropometric } \\
\hline $\mathrm{BMl}\left(\mathrm{kg} / \mathrm{m}^{2}\right)$ & $26.8 \pm 6.5$ & $27.1 \pm 6.2$ & 0.79 \\
\hline \multicolumn{4}{|l|}{ Medical history } \\
\hline \multicolumn{4}{|l|}{ Diabetes } \\
\hline Age at diabetes diagnosis (years) & $19.9 \pm 12.3$ & $17.5 \pm 9.9$ & 0.26 \\
\hline Duration of diabetes at enrollment (years) & $20.7 \pm 11.9$ & $23.0 \pm 12.5$ & 0.34 \\
\hline Presence of peripheral neuropathy & $24(48.0)$ & $28(45.2)$ & 0.85 \\
\hline Use of insulin & $47(94.0)$ & $60(96.8)$ & 0.65 \\
\hline Infectious prodrome & $7(14.0)$ & $9(14.5)$ & 1.00 \\
\hline Onset of symptoms & & & 0.26 \\
\hline Acute start & $21(42.0)$ & $33(53.2)$ & \\
\hline Insidious & $29(58.0)$ & $29(46.8)$ & \\
\hline Glucose (mg/dl) & $179.5 \pm 96.8$ & $171.7 \pm 81.6$ & 0.65 \\
\hline $\mathrm{HbA} 1 \mathrm{c}(\%)$ & $8.3 \pm 2.0$ & $8.1 \pm 1.8$ & 0.43 \\
\hline \multicolumn{4}{|l|}{ History of gastroparesis } \\
\hline Age at diagnosis of gastroparesis (years) & $33.7 \pm 12.1$ & $34.4 \pm 10.7$ & 0.74 \\
\hline Duration of gastroparesis at enrollment (years) & $7.2 \pm 7.3$ & $6.3 \pm 5.2$ & 0.43 \\
\hline \multicolumn{4}{|l|}{ Gastric emptying (mean\% retained) } \\
\hline 2-h emptying & $61.4 \pm 25.6$ & $60.2 \pm 28.1$ & 0.81 \\
\hline 4-h emptying & $36.2 \pm 28.3$ & $37.7 \pm 30.5$ & 0.79 \\
\hline Delayed gastric emptyinga & $41(82.0)$ & $49(79.0)$ & 0.81 \\
\hline C-peptide, low ( $\leq 0.8 \mathrm{ng} / \mathrm{ml})$ & $43(87.8)$ & $45(72.6)$ & 0.06 \\
\hline \multicolumn{4}{|l|}{ PAGI-SYM symptom severity (0-5) } \\
\hline Nausea severity & $3.3 \pm 1.3$ & $3.5 \pm 1.4$ & 0.52 \\
\hline Retching severity & $2.3 \pm 1.7$ & $2.4 \pm 1.7$ & 0.76 \\
\hline Vomiting severity & $2.6 \pm 1.9$ & $2.7 \pm 1.8$ & 0.73 \\
\hline Feeling of stomach fullness severity & $3.3 \pm 1.5$ & $3.2 \pm 1.5$ & 0.69 \\
\hline Inability to finish meal severity & $2.8 \pm 1.5$ & $2.9 \pm 1.7$ & 0.71 \\
\hline Excessively full after meal severity & $3.4 \pm 1.5$ & $3.5 \pm 1.5$ & 0.75 \\
\hline Loss of appetite severity & $3.0 \pm 1.6$ & $2.7 \pm 1.6$ & 0.37 \\
\hline Bloating severity & $3.0 \pm 1.5$ & $3.1 \pm 1.6$ & 0.73 \\
\hline Visibly larger stomach severity & $2.6 \pm 1.7$ & $2.7 \pm 1.8$ & 0.67 \\
\hline Upper abdominal pain & $2.7 \pm 1.8$ & $2.9 \pm 1.8$ & 0.66 \\
\hline Upper abdominal discomfort & $2.9 \pm 1.7$ & $3.0 \pm 1.7$ & 0.89 \\
\hline Cardinal symptom index (GCSI) (0-5) & $2.9 \pm 1.1$ & $3.0 \pm 1.0$ & 0.73 \\
\hline Nausea/vomiting GCSI subscale & $2.8 \pm 1.5$ & $2.9 \pm 1.5$ & 0.65 \\
\hline Bloating GCSI subscale & $2.8 \pm 1.5$ & $2.9 \pm 1.6$ & 0.69 \\
\hline Postprandial fullness GCSI subscale & $3.1 \pm 1.3$ & $3.1 \pm 1.2$ & 0.86 \\
\hline
\end{tabular}

a Gastric emptying scintigraphy of $>60 \%$ at $2 \mathrm{~h}$ OR $>10 \%$ at $4 \mathrm{~h}$.

GCSI, Gastroparesis Cardinal Symptom Index.

Within T1DM, there was no difference between GADA positive and GADA negative subjects in duration of symptoms, symptom scores and prevalence of delayed gastric emptying.

In regard to T2DM, about $13 \%$ were GADA positive and $8 \%$ had low $\mathrm{C}$-peptide levels. It is conceivable that those may belong to the category of LADA.

Within T2DM, GADA positives had longer duration of symptoms, but similar prevalence of gastric emptying. They also have similar symptom scores with the exception of upper abdominal pain which was higher in the GADA positive group. Also within this group, GADA positivity and prevalence of low C-peptide were similar when compared between those with delayed gastric emptying and those without.

Within T2DM, comparison between those with low C-peptide vs normal/high C-peptide showed similar duration of symptoms and prevalence of delayed gastric emptying. But, there was more prevalent severity of bloating and visibly larger stomach in those with normal/high C-peptide. These results should be interpreted with caution because of the low number of patients with T2DM who have low C-peptide. 
TABLE 3 | Baseline characteristics of patients with T2DM by level of GAD-65 Antibodies.

\begin{tabular}{|c|c|c|c|}
\hline Baseline characteristic & $\begin{array}{l}\text { Positive GAD-65 Antibodies } \\
\text { (GADA > 1.0) }(n=12) \\
N(\%) \text { or mean } \pm \text { SD }\end{array}$ & $\begin{array}{l}\text { Negative GAD-65 Antibodies } \\
\text { (GADA } \leq 1.0)(n=78) \\
N(\%) \text { or mean } \pm \text { SD }\end{array}$ & $p$-Value \\
\hline \multicolumn{4}{|l|}{ Demographic } \\
\hline Gender: female & $8(66.7)$ & $58(74.4)$ & 0.73 \\
\hline Mean age at enrollment & $51.2 \pm 12.3$ & $52.1 \pm 9.6$ & 0.76 \\
\hline Ethnicity: Hispanic vs other & $5(41.7)$ & $7(9.0)$ & 0.009 \\
\hline Race & & & 0.32 \\
\hline White & $8(66.7)$ & $62(80.5)$ & \\
\hline Black & $4(33.3)$ & $12(15.6)$ & \\
\hline Other & $0(-)$ & $3(3.9)$ & \\
\hline \multicolumn{4}{|l|}{ Anthropometric } \\
\hline $\mathrm{BMl}\left(\mathrm{kg} / \mathrm{m}^{2}\right)$ & $31.9 \pm 9.3$ & $33.5 \pm 7.5$ & 0.51 \\
\hline \multicolumn{4}{|l|}{ Medical history } \\
\hline \multicolumn{4}{|l|}{ Diabetes } \\
\hline Age at diabetes diagnosis (years) & $38.9 \pm 11.0$ & $39.7 \pm 10.5$ & 0.80 \\
\hline Duration of diabetes at enrollment (years) & $12.3 \pm 9.3$ & $12.4 \pm 7.3$ & 0.96 \\
\hline Presence of peripheral neuropathy & $1(8.3)$ & $31(39.7)$ & 0.05 \\
\hline Use of insulin & $5(41.7)$ & $45(57.7)$ & 0.36 \\
\hline Onset of symptoms & & & 0.28 \\
\hline Acute start & $5(41.7)$ & $41(52.6)$ & \\
\hline Insidious & $6(50.0)$ & $36(46.2)$ & \\
\hline Glucose (mg/dl) & $148.8 \pm 80.4$ & $148.4 \pm 71.1$ & 0.99 \\
\hline $\mathrm{HbA} 1 \mathrm{c}(\%)$ & $7.3 \pm 1.6$ & $7.6 \pm 1.8$ & 0.56 \\
\hline \multicolumn{4}{|l|}{ History of gastroparesis } \\
\hline Age at diagnosis of gastroparesis (years) & $44.1 \pm 12.5$ & $48.3 \pm 10.1$ & 0.19 \\
\hline Duration of gastroparesis at enrollment (years) & $7.1 \pm 6.7$ & $3.8 \pm 2.9$ & 0.004 \\
\hline \multicolumn{4}{|l|}{ Gastric emptying (mean\% retained) } \\
\hline 2-h emptying & $44.5 \pm 21.3$ & $49.0 \pm 26.0$ & 0.56 \\
\hline 4-h emptying & $13.8 \pm 11.6$ & $22.5 \pm 22.1$ & 0.19 \\
\hline Delayed gastric emptying ${ }^{a}$ & $6(50.0)$ & $54(69.2)$ & 0.20 \\
\hline C-Peptide, low ( $\leq 0.8$ ng/ml) & $1(8.3)$ & $6(7.7)$ & 1.00 \\
\hline \multicolumn{4}{|l|}{ PAGI-SYM symptom severity (0-5) } \\
\hline Nausea severity & $3.2 \pm 1.2$ & $3.1 \pm 1.4$ & 0.93 \\
\hline Retching severity & $1.9 \pm 1.7$ & $2.2 \pm 1.6$ & 0.56 \\
\hline Vomiting severity & $2.1 \pm 2.0$ & $1.9 \pm 1.7$ & 0.81 \\
\hline Feeling of stomach fullness severity & $3.9 \pm 0.8$ & $3.5 \pm 1.3$ & 0.32 \\
\hline Inability to finish meal severity & $3.3 \pm 1.5$ & $3.3 \pm 1.4$ & 0.87 \\
\hline Excessively full after meal severity & $3.7 \pm 1.1$ & $3.6 \pm 1.2$ & 0.92 \\
\hline Loss of appetite severity & $2.7 \pm 1.5$ & $2.8 \pm 1.5$ & 0.72 \\
\hline Bloating severity & $3.9 \pm 0.9$ & $3.3 \pm 1.6$ & 0.19 \\
\hline Visibly larger stomach severity & $3.6 \pm 1.3$ & $2.8 \pm 1.8$ & 0.17 \\
\hline Upper abdominal pain & $3.7 \pm 1.6$ & $2.5 \pm 1.7$ & 0.03 \\
\hline Upper abdominal discomfort & $3.7 \pm 1.5$ & $2.8 \pm 1.6$ & 0.08 \\
\hline Cardinal symptom index (GCSI) (0-5) & $3.2 \pm 0.9$ & $2.9 \pm 1.1$ & 0.48 \\
\hline Nausea/vomiting GCSI subscale & $2.4 \pm 1.4$ & $2.4 \pm 1.3$ & 0.93 \\
\hline Bloating GCSI subscale & $3.8 \pm 1.0$ & $3.1 \pm 1.6$ & 0.16 \\
\hline Postprandial fullness GCSI subscale & $3.4 \pm 1.1$ & $3.3 \pm 1.2$ & 0.90 \\
\hline
\end{tabular}

${ }^{a}$ Gastric emptying scintigraphy (GES) of $>60 \%$ at $2 h$ OR $>10 \%$ at $4 \mathrm{~h}$.

The reported occurrence of LADA in T2DM has been varied. The prevalence of autoantibodies has been reported as anywhere from 3 to $31 \%$ with rates varying greatly by geographic area. In studies specific to North America, LADA has been reported in $3.4,4.7,5.9,16$, and $20 \%$ of patients $(2,3)$. In the present study, we found that $13 \%$ of subjects with phenotypic T2DM were GADA positive. This rate falls within the mid-range of previously reported rates and demonstrates that LADA is not as rare as once thought. In our patients, the rate of gastroparesis was not different between GAD positive and GAD negative phenotypic T2DM patients and we were unable to support our hypothesis that GADA positivity in phenotypically T2DM patients may predispose to gastroparesis.

The diagnosis of LADA mainly relies on seropositivity of antibodies (14). There are three main serum autoantibodies reflecting humoral immunity of LADA: anti-GAD65 antibody (GADA), insulinoma 2-associated antibodies (IA-2A), and insulin autoantibody (IAA). Others include ICA (islet cell cytoplasmic autoantibodies), and zinc transporter 8 autoantibody (ZnT8A). GADA, which is a specific antibody against GAD-65 is recognized as the most sensitive immune parameter for the diagnosis of T1DM and LADA, because it appears early and remains for a long duration 
TABLE 4 | Baseline characteristics of patients with Type 2 Diabetes (T2DM) by presence of delayed gastric emptying.

\begin{tabular}{|c|c|c|c|}
\hline Baseline characteristic & $\begin{array}{c}\text { Normal emptying }(n=30) \\
N(\%) \text { or mean } \pm \text { SD }\end{array}$ & $\begin{array}{l}\text { Delayed emptying }{ }^{\mathrm{a}}(n=60) \\
N(\%) \text { or mean } \pm \text { SD }\end{array}$ & $p$-Value \\
\hline \multicolumn{4}{|l|}{ Demographic } \\
\hline Gender: female & $18(60.0)$ & $48(80.0)$ & 0.08 \\
\hline Mean age at enrollment & $50.5 \pm 8.5$ & $52.8 \pm 10.6$ & 0.30 \\
\hline Ethnicity: Hispanic vs other & $5(16.7)$ & $7(11.7)$ & 0.53 \\
\hline Race & & & 0.43 \\
\hline White & $23(76.7)$ & $47(79.7)$ & \\
\hline Black & 7 (23.3) & $9(15.3)$ & \\
\hline Other & $0(0)$ & $3(5.1)$ & \\
\hline \multicolumn{4}{|l|}{ Anthropometric } \\
\hline $\mathrm{BMl}\left(\mathrm{kg} / \mathrm{m}^{2}\right)$ & $33.6 \pm 8.3$ & $33.2 \pm 7.5$ & 0.81 \\
\hline \multicolumn{4}{|l|}{ Medical history } \\
\hline \multicolumn{4}{|l|}{ Diabetes } \\
\hline Age at diabetes diagnosis (years) & $40.0 \pm 8.7$ & $39.4 \pm 11.4$ & 0.81 \\
\hline Duration of diabetes at enrollment (years) & $10.5 \pm 6.0$ & $13.3 \pm 8.1$ & 0.09 \\
\hline Presence of peripheral neuropathy & 10 (33.3) & $22(36.7)$ & 0.82 \\
\hline Use of insulin & $18(60.0)$ & $32(53.3)$ & 0.65 \\
\hline Onset of symptoms & & & 0.24 \\
\hline Acute start & $19(63.3)$ & $27(45.0)$ & \\
\hline Insidious & $11(36.7)$ & $31(51.7)$ & \\
\hline Other & $0(-)$ & 2 (3.3) & \\
\hline Glucose (mg/dl) & $144.3 \pm 48.9$ & $150.5 \pm 81.3$ & 0.70 \\
\hline $\mathrm{HbA1c}(\%)$ & $7.6 \pm 1.5$ & $7.6 \pm 1.9$ & 0.93 \\
\hline \multicolumn{4}{|l|}{ History of gastroparesis } \\
\hline Age at diagnosis of gastroparesis (years) & $45.3 \pm 9.5$ & $49.0 \pm 10.8$ & 0.12 \\
\hline Duration of gastroparesis at enrollment (years) & $5.2 \pm 4.9$ & $3.8 \pm 2.9$ & 0.11 \\
\hline \multicolumn{4}{|l|}{ Gastric emptying (mean\% retained) } \\
\hline 2-h emptying & $26.1 \pm 18.1$ & $59.6 \pm 20.7$ & $<0.001$ \\
\hline 4-h emptying & $3.6 \pm 3.0$ & $30.3 \pm 20.8$ & $<0.001$ \\
\hline GADA positive (>1.0 U/ml) & $6(20.0)$ & $6(10.0)$ & 0.20 \\
\hline C-Peptide, low ( $\leq 0.8$ ng/ml) & $1(3.3)$ & $6(10.0)$ & 0.42 \\
\hline \multicolumn{4}{|l|}{ PAGI-SYM symptom severity (0-5) } \\
\hline Nausea severity & $3.1 \pm 1.3$ & $3.1 \pm 1.4$ & 1.00 \\
\hline Retching severity & $1.8 \pm 1.6$ & $2.3 \pm 1.6$ & 0.16 \\
\hline Vomiting severity & $1.5 \pm 1.6$ & $2.2 \pm 1.8$ & 0.07 \\
\hline Feeling of stomach fullness severity & $3.6 \pm 1.1$ & $3.6 \pm 1.3$ & 0.81 \\
\hline Inability to finish meal severity & $3.2 \pm 1.6$ & $3.4 \pm 1.3$ & 0.71 \\
\hline Excessively full after meal severity & $3.7 \pm 1.1$ & $3.6 \pm 1.3$ & 0.59 \\
\hline Loss of appetite severity & $2.8 \pm 1.6$ & $2.8 \pm 1.4$ & 0.92 \\
\hline Bloating severity & $3.4 \pm 1.4$ & $3.4 \pm 1.6$ & 0.92 \\
\hline Visibly larger stomach severity & $3.0 \pm 1.7$ & $2.9 \pm 1.8$ & 0.80 \\
\hline Upper abdominal pain & $2.6 \pm 1.8$ & $2.7 \pm 1.7$ & 0.76 \\
\hline Upper abdominal discomfort & $2.8 \pm 1.6$ & $3.0 \pm 1.6$ & 0.61 \\
\hline Cardinal symptom index [Gastroparesis & $2.9 \pm 1.0$ & $3.0 \pm 1.1$ & 0.64 \\
\hline \multicolumn{4}{|l|}{ Cardinal Symptom Index (GCSI)] (0-5) } \\
\hline Nausea/vomiting GCSI subscale & $2.2 \pm 1.2$ & $2.6 \pm 1.4$ & 0.18 \\
\hline Bloating GCSI subscale & $3.2 \pm 1.5$ & $3.2 \pm 1.6$ & 0.92 \\
\hline Postprandial fullness GCSI subscale & $3.3 \pm 1.2$ & $3.3 \pm 1.1$ & 0.88 \\
\hline
\end{tabular}

${ }^{a}$ Delayed gastric emptying defined as having gastric emptying scintigraphy of $>60 \%$ at $2 \mathrm{~h}$ OR $>10 \%$ at $4 \mathrm{~h}$.

in serum. The assay of GAD-65 antibody is the most standardized of all the autoantibodies. Furthermore, in our preliminary work conducted in subjects with gastroparesis and either T1DM or T2DM, no patients were positive for ICA or IAA (15). For these reasons, we limited our evaluation to the anti-GAD65 antibody in the current study.

Characteristics of GADA positive patients with phenotypically type 2 diabetes have been previously reported by several investigators. Arikan and colleagues found that GADA positive patients were significantly younger at age of diabetes onset, had a lower
BMI, and lower serum C-peptide levels than patients who were GADA negative with T2DM (4). Hawa and colleagues also found that GADA positive patients had a significantly lower mean age of onset of diabetes as well as lower BMI in their cohort of European subjects (3). In contrast, Zinman and colleagues did find differences in adiposity between GADA positive and negative subjects with type 2 diabetes in the ADOPT study but did find lesser degrees of insulin resistance and a lower probability of the metabolic syndrome (2). In our population, GADA positive patients tended to be younger at diabetes diagnosis and had a lower BMI, 
TABLE 5 | Baseline characteristics of patients with Type 1 Diabetes (T1DM) by presence of delayed gastric emptying.

\begin{tabular}{|c|c|c|c|}
\hline Baseline characteristic & $\begin{array}{c}\text { Normal emptying }(n=22) \\
N(\%) \text { or Mean } \pm \text { SD }\end{array}$ & $\begin{array}{l}\text { Delayed Emptying }^{\mathrm{a}}(\boldsymbol{n}=91) \\
N(\%) \text { or Mean } \pm \text { SD }\end{array}$ & $p$-Value \\
\hline \multicolumn{4}{|l|}{ Demographic } \\
\hline Gender: female & $18(81.8)$ & $60(65.9)$ & 0.20 \\
\hline Mean age at enrollment & $44.3 \pm 14.0$ & $39.4 \pm 11.5$ & 0.08 \\
\hline Ethnicity: Hispanic vs other & 4 (18.2) & $13(14.3)$ & 0.74 \\
\hline Race & & & 0.82 \\
\hline White & $18(81.8)$ & $66(74.2)$ & \\
\hline Black & $3(13.6)$ & $18(20.2)$ & \\
\hline Other & $1(4.6)$ & $5(5.6)$ & \\
\hline \multicolumn{4}{|l|}{ Anthropometric } \\
\hline $\mathrm{BMI}\left(\mathrm{kg} / \mathrm{m}^{2}\right)$ & $29.1 \pm 6.8$ & $26.3 \pm 6.1$ & 0.06 \\
\hline \multicolumn{4}{|l|}{ Medical history } \\
\hline \multicolumn{4}{|l|}{ Diabetes } \\
\hline Age at diabetes diagnosis (years) & $19.2 \pm 13.4$ & $18.3 \pm 10.5$ & 0.73 \\
\hline Duration of diabetes at enrollment (years) & $25.2 \pm 15.0$ & $21.1 \pm 11.4$ & 0.16 \\
\hline Presence of peripheral neuropathy & $13(59.1)$ & $40(44.0)$ & 0.24 \\
\hline Use of insulin & $22(100.0)$ & $86(94.5)$ & 0.58 \\
\hline Onset of symptoms & & & 0.03 \\
\hline Acute start & $6(27.3)$ & 49 (53.9) & \\
\hline Insidious & $16(72.7)$ & $42(46.2)$ & \\
\hline Glucose (mg/dl) & $187.1 \pm 108.9$ & $172.0 \pm 82.6$ & 0.47 \\
\hline $\mathrm{HbA1c}(\%)$ & $8.3 \pm 1.6$ & $8.2 \pm 1.9$ & 0.77 \\
\hline \multicolumn{4}{|l|}{ History of gastroparesis } \\
\hline Age at diagnosis of gastroparesis (years) & $36.4 \pm 15.1$ & $33.4 \pm 10.3$ & 0.27 \\
\hline Duration of gastroparesis at enrollment (years) & $8.4 \pm 7.6$ & $6.3 \pm 5.8$ & 0.17 \\
\hline \multicolumn{4}{|l|}{ Gastric emptying (mean\% retained) } \\
\hline 2-h emptying & $23.1 \pm 16.2$ & $70.1 \pm 20.1$ & $<0.001$ \\
\hline 4-h emptying & $4.1 \pm 2.8$ & $45.3 \pm 27.2$ & $<0.001$ \\
\hline GADA positive (>1.0 U/ml) & $9(40.9)$ & 41 (45.6) & 0.81 \\
\hline C-Peptide, low ( $\leq 0.8$ ng/ml) & $18(81.8)$ & $70(78.7)$ & 1.00 \\
\hline \multicolumn{4}{|l|}{ PAGI-SYM symptom severity (0-5) } \\
\hline Nausea severity & $3.3 \pm 1.6$ & $3.4 \pm 1.3$ & 0.65 \\
\hline Retching severity & $2.1 \pm 1.8$ & $2.4 \pm 1.7$ & 0.51 \\
\hline Vomiting severity & $2.5 \pm 2.0$ & $2.7 \pm 1.8$ & 0.56 \\
\hline Feeling of stomach fullness severity & $3.6 \pm 1.3$ & $3.2 \pm 1.5$ & 0.17 \\
\hline Inability to finish meal severity & $3.0 \pm 1.4$ & $2.8 \pm 1.6$ & 0.60 \\
\hline Excessively full after meal severity & $3.6 \pm 1.5$ & $3.3 \pm 1.5$ & 0.41 \\
\hline Loss of appetite severity & $2.9 \pm 1.6$ & $2.8 \pm 1.6$ & 0.78 \\
\hline Bloating severity & $3.5 \pm 1.5$ & $2.9 \pm 1.6$ & 0.07 \\
\hline Visibly larger stomach severity & $3.2 \pm 1.7$ & $2.5 \pm 1.7$ & 0.09 \\
\hline Upper abdominal pain & $2.8 \pm 1.6$ & $2.8 \pm 1.8$ & 0.99 \\
\hline Upper abdominal discomfort & $3.0 \pm 1.6$ & $3.0 \pm 1.7$ & 0.93 \\
\hline Cardinal symptom index [Gastroparesis & $3.1 \pm 1.2$ & $2.9 \pm 1.1$ & 0.34 \\
\hline \multicolumn{4}{|l|}{ Cardinal Symptom Index (GCSI)] (0-5) } \\
\hline Nausea/vomiting GCSI subscale & $2.6 \pm 1.7$ & $2.8 \pm 1.5$ & 0.53 \\
\hline Bloating GCSI subscale & $3.4 \pm 1.5$ & $2.7 \pm 1.6$ & 0.07 \\
\hline Postprandial fullness GCSI subscale & $3.3 \pm 1.3$ & $3.0 \pm 1.2$ & 0.36 \\
\hline
\end{tabular}

${ }^{2}$ Delayed gastric emptying defined as having gastric emptying scintigraphy of $>60 \%$ at $2 \mathrm{~h}$ OR $>10 \%$ at $4 \mathrm{~h}$.

even though not statistically significant. In addition, GADA positive patients had a significantly longer duration of gastroparesis at enrollment $(7.1 \pm 6.7$ vs $3.8 \pm 2.9$ years; $p=0.004)$ than did negative subjects. When comparing phenotypic T2DM subjects, GADA positive patients, had a longer duration of gastroparesis, lower prevalence of peripheral neuropathy, and were more likely to be Hispanic than GADA negative subjects.

In addition to phenotypic characteristics, some investigators have examined the occurrence of the long-term complications among patients who are GADA positive vs negative. In 2003, Arkian et al. reported a higher rate of retinopathy and nephropathy among their GADA positive patients; however, the rate of peripheral neuropathy did not differ between the two groups (4). In the Fermantle Diabetes Study (16), the prevalence of retinopathy was increased twofold among GADA positive patients as compared to negative patients. However, several other studies have found comparable rates of retinopathy and nephropathy among GAD65 positive and negative patients (17-19). In the most recent study and to date the only large prospective trial (3), the incidence of microvascular disease did not differ between GADA positive and negative patients. In addition, the rate of progression to macrovascular events was similar in both groups. In regards to 
TABLE 6 | Baseline characteristics of patients with Type 1 Diabetes (T1DM) by level of C-Peptide.

\begin{tabular}{|c|c|c|c|}
\hline Baseline characteristic & $\begin{array}{l}\text { Low C-peptide }(\leq 0.8 \mathrm{ng} / \mathrm{ml})^{\mathrm{a}}(n=88) \\
\qquad N(\%) \text { or Mean } \pm \mathrm{SD}\end{array}$ & $\begin{array}{c}\text { Normal/high C-peptide }(>0.8 \mathrm{ng} / \mathrm{ml})^{\mathrm{a}}(n=23) \\
N(\%) \text { or Mean } \pm \text { SD }\end{array}$ & $p$-Value \\
\hline \multicolumn{4}{|l|}{ Demographic } \\
\hline Gender: female & $63(71.6)$ & $13(56.5)$ & 0.21 \\
\hline Mean age at enrollment & $40.0 \pm 12.3$ & $42.6 \pm 11.0$ & 0.36 \\
\hline Ethnicity: Hispanic vs other & $8(9.1)$ & $8(34.8)$ & 0.005 \\
\hline Race & & & 0.39 \\
\hline White & $69(78.4)$ & $14(66.7)$ & \\
\hline Black & $15(17.1)$ & $5(23.8)$ & \\
\hline Other & $4(4.6)$ & $2(9.5)$ & \\
\hline \multicolumn{4}{|l|}{ Anthropometric } \\
\hline BMI $\left(\mathrm{kg} / \mathrm{m}^{2}\right)$ & $26.9 \pm 6.5$ & $27.2 \pm 6.0$ & 0.87 \\
\hline \multicolumn{4}{|l|}{ Medical history } \\
\hline \multicolumn{4}{|l|}{ Diabetes } \\
\hline Age at diabetes diagnosis (years) & $17.2 \pm 10.5$ & $24.0 \pm 11.9$ & 0.008 \\
\hline Duration of diabetes at enrollment (years) & $22.8 \pm 12.6$ & $18.6 \pm 10.7$ & 0.15 \\
\hline Presence of peripheral neuropathy & $40(45.5)$ & $12(52.2)$ & 0.64 \\
\hline Use of insulin & $88(100.0)$ & $18(78.3)$ & $<0.001$ \\
\hline Onset of symptoms & & & 1.00 \\
\hline Acute start & $42(47.7)$ & $11(47.8)$ & \\
\hline Insidious & $46(52.3)$ & $12(52.2)$ & \\
\hline Glucose (mg/dl) & $172.5 \pm 83.6$ & $174.9 \pm 94.8$ & 0.90 \\
\hline $\mathrm{HbA1c}(\%)$ & $8.3 \pm 1.6$ & $7.5 \pm 2.4$ & 0.04 \\
\hline \multicolumn{4}{|l|}{ History of gastroparesis } \\
\hline Age at diagnosis of gastroparesis (years) & $33.4 \pm 11.5$ & $37.3 \pm 10.1$ & 0.14 \\
\hline Duration of gastroparesis at enrollment (years) & $7.0 \pm 6.2$ & $5.4 \pm 6.4$ & 0.27 \\
\hline \multicolumn{4}{|l|}{ Gastric emptying (mean\% retained) } \\
\hline 2-h emptying & $60.9 \pm 26.5$ & $60.4 \pm 29.5$ & 0.93 \\
\hline 4-h emptying & $35.6 \pm 29.5$ & $42.3 \pm 29.8$ & 0.33 \\
\hline Delayed gastric emptying ${ }^{b}$ & 70 (79.6) & $19(82.6)$ & 1.00 \\
\hline GADA positive (>1.0 U/ml) & $43(48.9)$ & $6(26.1)$ & 0.06 \\
\hline \multicolumn{4}{|l|}{ PAGI-SYM symptom severity $(0-5)$} \\
\hline Nausea severity & $3.4 \pm 1.3$ & $3.4 \pm 1.5$ & 0.93 \\
\hline Retching severity & $2.3 \pm 1.7$ & $2.7 \pm 1.8$ & 0.28 \\
\hline Vomiting severity & $2.6 \pm 1.9$ & $3.1 \pm 1.6$ & 0.25 \\
\hline Feeling of stomach fullness severity & $3.2 \pm 1.5$ & $3.3 \pm 1.3$ & 0.85 \\
\hline Inability to finish meal severity & $2.8 \pm 1.6$ & $3.2 \pm 1.4$ & 0.25 \\
\hline Excessively full after meal severity & $3.4 \pm 1.6$ & $3.6 \pm 1.0$ & 0.57 \\
\hline Loss of appetite severity & $2.8 \pm 1.7$ & $3.0 \pm 1.4$ & 0.57 \\
\hline Bloating severity & $3.0 \pm 1.6$ & $2.9 \pm 1.5$ & 0.64 \\
\hline Visibly larger stomach severity & $2.6 \pm 1.8$ & $2.7 \pm 1.6$ & 0.82 \\
\hline Upper abdominal pain & $2.8 \pm 1.8$ & $3.0 \pm 1.8$ & 0.55 \\
\hline Upper abdominal discomfort & $3.0 \pm 1.7$ & $3.0 \pm 1.8$ & 0.98 \\
\hline Cardinal symptom index [Gastroparesis & $2.9 \pm 1.1$ & $3.0 \pm 0.9$ & 0.52 \\
\hline \multicolumn{4}{|l|}{ Cardinal Symptom Index (GCSI)] (0-5) } \\
\hline Nausea/vomiting GCSI subscale & $2.8 \pm 1.5$ & $3.1 \pm 1.5$ & 0.39 \\
\hline Bloating GCSI subscale & $2.8 \pm 1.7$ & $2.8 \pm 1.4$ & 0.91 \\
\hline Postprandial fullness GCSI subscale & $3.0 \pm 1.3$ & $3.3 \pm 0.9$ & 0.44 \\
\hline
\end{tabular}

aNegative C-Peptide defined as c-peptide levels $\leq 0.8 \mathrm{ng} / \mathrm{ml}$.

${ }^{b}$ Gastric emptying scintigraphy of $>60 \%$ at $2 h$ OR $>10 \%$ at $4 \mathrm{~h}$.

GCSI, Gastroparesis Cardinal Symptom Index.

peripheral neuropathy, one study actually found fewer features of neuropathy among GADA positive patients (20). Our study specifically examined the relationship between gastroparesis (a form of autonomic neuropathy) and autoantibody positivity. We found no differences in rates of delayed gastric emptying, or in percent retained at either 2 or $4 \mathrm{~h}$ among the GADA positive and GADA negative phenotypically T2DM patients. In addition, there were no differences in symptom severity scores (PAGI-SYM) or in the GCSI between the two groups. We also did not find that rates of peripheral neuropathy differed between GADA positive and negative subjects.

A surprising finding of the study was the portion of subjects who apparently were misclassified in regards to their type of diabetes. For the registry, classification of diabetes was obtained from medical records and/or by patient self-report. Twenty five of the 113 subjects with type 1 diabetes had normal and or elevated C-peptide levels. Since individuals in this group had been diagnosed on average 22 years prior to this assessment, 
one would have anticipated low c-peptide levels. Thus, $22 \%$ of individuals who classified themselves and/or were classified by their health-care provider as having type 1 diabetes probably had T2DM. In addition 7 of the 90 subjects (8\%) with the diagnosis of T2DM had low C-peptide levels. However, because of the long duration of diabetes (mean 13.4 years) in this group, it is possible that these individuals had higher levels at diagnosis and that the current low C-peptide levels represented the progressive beta-cell loss seen in T2DM making it impossible to determine if they were misclassified. It must be acknowledged that this potential misclassification is a limitation of this and perhaps other studies involving diabetes. We did not perform any genetic testing or family history to help make the diagnosis of maturity-onset diabetes of the young (MODY). MODY is a form of diabetes classically presents as non-insulin-requiring diabetes in lean individuals typically younger than 25 with evidence of autosomal dominant inheritance. MODY accounts about $1 \%$ of all cases of diabetes mellitus (21).

In conclusion, GAD65 antibodies were present in 13\% of our phenotypic T2DM patients with symptoms of gastroparesis suggesting presence of LADA. GADA positivity in phenotypic T2DM patients did not associate with delayed gastric emptying or gastroparesis symptom severity. Low C-peptide was associated with insulin use. Some patients labeled as T1DM had normal C-peptide levels suggesting a misclassification. Both the C-peptide levels and GADA positivity could be helpful in correct classification of diabetes.

\section{ETHICS STATEMENT}

The Gastroparesis Clinical Research Consortium (GpCRC) Gastroparesis Registry protocol and consents were approved by

\section{REFERENCES}

1. Leslie RDG, Kolb H, Schollot NC, Buzzetti R, Mauricio D, De Leiva A, et al. Diabetes classification: grey zones, sound and smoke: action LADA. Diabetes Metab Res Rev (2008) 24:511-9. doi:10.1002/dmrr.877

2. Zinman B, Kahn SE, Haffner SM, O’Neill MC, Heise MA, Freed MI. Phenotypic characteristics of GAD antibody-positive recently diagnosed patients with type 2 diabetes in North America and Europe. Diabetes (2004) 53:3193-201. doi:10.2337/diabetes.53.12.3193

3. Hawa MI, Buchan AP, Ola T, Wun CC, DeMicco DA, Bao W, et al. LADA and CARDS: a prospective study of clinical outcome in established adult-onset autoimmune diabetes. Diabetes Care (2014) 37:1643-9. doi:10.2337/dc13-2383

4. Arikan E, Sabuncu T, Ozer EM, Hatemi H. The clinical characteristics of latent autoimmune diabetes in adults and is relation with chronic complications in metabolically poor controlled Turkish patients with Type 2 diabetes mellitus. J Diabetes Complication (2005) 19:254-8. doi:10.1016/j.jdiacomp.2005.02.004

5. Andersen CD, Bennet L, Nyström L, Lindblad U, Lindholm E, Groop L, et al. Worse glycaemic control in LADA patients than in those with type 2 diabetes, despite a longer time on insulin therapy. Diabetologia (2013) 56:252-8. doi:10.1007/s00125-012-2759-y

6. Parkman HP, Hasler WL, Fisher RS. American Gastroenterological Association technical review on the diagnosis and treatment of gastroparesis. Gastroenterology (2004) 127:1592-622. doi:10.1053/j.gastro.2004.09.055

7. Soota K, Kedar A, Nikitina Y, Arendale E, Vedanarayanan V, Abell TL. Immunomodulation for treatment of drug and device refractory gastroparesis. Results Immunol (2016) 6:11-4. doi:10.1016/j.rinim.2016.02.001 the GpCRC Steering Committee and by the NIDDK-appointed Data and Safety Monitoring Board. Also, they were reviewed and approved by each institution's IRB, including the Data Coordinating Center's IRB. All subjects gave written informed consent in accordance with the Declaration of Helsinki.

\section{AUTHOR CONTRIBUTIONS}

ES: data interpretation and writing and revising manuscript. $\mathrm{CH}$ : study conceptualization, data interpretation, and writing manuscript. LW and PM: statistical analysis, data interpretation, and writing manuscript. AR and JCalles: data interpretation and revising manuscript. GF and FH: revising manuscript. $\mathrm{WH}, \mathrm{KK}$, LN, WS, TA, IS, RM, PP, and JClarke: patient recruitment and revising manuscript. JT: statistical analysis, data interpretation, and revising manuscript. HP: study conceptualization, patient recruitment, data interpretation, and writing manuscript.

\section{ACKNOWLEDGMENTS}

Preliminary results of this study were presented as an abstract at the 2016 Digestive Disease Week (22).

\section{FUNDING}

Funding for this study was received from NIH Diabetes Complication Consortium and the NIH Gastroparesis Research Consortium. The Gastroparesis Clinical Research Consortium (GpCRC) is supported by the National Institute of Diabetes and Digestive and Kidney Diseases (NIDDK) (grants U01DK073983, U01DK073975, U01DK073985, U01DK074007, U01DK073974, U01DK074008).
8. Parkman HP, Yates K, Hasler WL, Nguyen L, Pasricha PJ, Snape WJ, et al. Similarities and differences between diabetic and idiopathic gastroparesis. Clin Gastroenterol Hepatol (2011) 9:1056-64. doi:10.1016/j.cgh.2011.08.013

9. Pasricha PJ, Colvin R, Yates K, Hasler WL, Abell TL, Ünalp-Arida A, et al. Characteristics of patients with chronic unexplained nausea and vomiting and normal gastric emptying. Clin Gastroenterol Hepatol (2011) 9:567-76. doi:10.1016/j.cgh.2011.03.003

10. Rentz AM, Kahrilas P, Stanghellini V, Tack J, Talley NJ, de la Loge C, et al. Development and psychometric evaluation of the patient assessment of upper gastrointestinal symptom severity index (PAGI-SYM) in patients with upper gastrointestinal disorders. Qual Life Res (2004) 13:1737-49. doi:10.1007/ s11136-004-9567-x

11. Revicki DA, Rentz AM, Dubois D, Kahrilas P, Stanghellini V, Talley NJ, et al. Development and validation of a patient-assessed gastroparesis symptom severity measure: the Gastroparesis Cardinal Symptom Index. Aliment Pharmacol Ther (2003) 18:141-50. doi:10.1046/j.1365-2036.2003.01612.x

12. Abell TL, Camilleri M, Donohoe K, Hasler WL, Lin HC, Maurer AH, et al. Consensus recommendations for gastric emptying scintigraphy. Am J Gastroenterol (2008) 103:753-63. doi:10.1111/j.1572-0241.2007.01636.x

13. Koch KL, Hasler WL, Yates KP, Parkman HP, Pasricha PJ, Calles-Escandon J, et al. Baseline features and differences in 48 week clinical outcomes in patients with gastroparesis and type 1 vs type 2 diabetes. Neurogastroenterol Motil (2016) 28(7):1001-15. doi:10.1111/nmo.12800

14. Liao Y, Xiang Y, Zhou Z. Diagnostic criteria of latent autoimmune diabetes in adults (LADA): a review and reflection. Front Med (2012) 6:243-7. doi:10.1007/s11684-012-0201-y 
15. Singla R, Homko C, Schey R, Parkman HP. Diabetes-related autoantibodies in diabetic gastroparesis. Dig Dis Sci (2015) 60:1733-7. doi:10.1007/ s10620-015-3690-0

16. Balme M, McAllister I, Davis WA, Davis TM. Retinopathy in latent autoimmune diabetes of adults: the Fretmantle Diabetes Study. Diabet Med (2002) 19:602-5. doi:10.1046/j.1464-5491.2002.00739.x

17. Isomaa B, Almgren P, Henricsson M, Taskinen MR, Tuomi T, Groop L, et al. Chronic complications in patients with slowly progressing autoimmune type 1 diabetes(LADA).Diabetes Care (1999) 22:1347-53. doi:10.2337/diacare.22.8.1347

18. Li X, Yang L, Zhou Z, Huang G, Yan X. Glutamic acid decarboxylase 65 autoantibody levels discriminate two subtypes of latent autoimmune diabetes in adults. Chin Med J (2003) 116:1728-32.

19. Owen KR, Stride A, Ellard S, Hattersley AT. Etiological investigation of diabetes in young adults presenting with apparent type 2 diabetes. Diabetes Care (2003) 26:2088-93. doi:10.2337/diacare.26.7.2088

20. Baum P, Herman W, Verlohren HJ, Wagner A, Lohmann T, Grahmann F. Diabetic neuropathy in patients with latent autoimmune diabetes of adults (LADA) compared with patients with type 1 and type 2 diabetes. J Neurol (2003) 250:682-7. doi:10.1007/s00415-003-1055-7
21. Kleinberger JW, Pollin TI. Undiagnosed MODY: time for action. Curr Diab Rep (2015) 15(12):110. doi:10.1007/s11892-015-0681-7

22. Homko C, May KP, Siraj E, Rao A, Hamilton C. Islet autoantibodies and C-peptide levels in patients with diabetes and symptoms of gastroparesis. Gastroenterology (2016) 150(4):S718. doi:10.1016/S0016-5085(16) 32450-7

Conflict of Interest Statement: The authors declare that the research was conducted in the absence of any commercial or financial relationships that could be construed as a potential conflict of interest.

Copyright (๑) 2018 Siraj, Homko, Wilson, May, Rao, Calles, Farrugia, Hasler, Koch, Nguyen, Snape, Abell, Sarosiek, McCallum, Pasricha, Clarke, Tonascia, Hamilton and Parkman. This is an open-access article distributed under the terms of the Creative Commons Attribution License (CC BY). The use, distribution or reproduction in other forums is permitted, provided the original author(s) and the copyright owner are credited and that the original publication in this journal is cited, in accordance with accepted academic practice. No use, distribution or reproduction is permitted which does not comply with these terms. 